\title{
Pedagogical Content Knowledge for Teaching Inclusive Design
}

\author{
Alannah Oleson, Christopher Mendez, Zoe \\ Steine-Hanson, Claudia Hilderbrand, \\ Christopher Perdriau, Margaret Burnett \\ School of Electrical Engineering and Computer Science \\ Oregon State University \\ Corvallis, Oregon \\ [olesona,mendezc,steinehz,minic,perdriac,burnett]@eecs. \\ oregonstate.edu
}

\author{
Amy J. Ko \\ The Information School \\ University of Washington \\ Seattle, Washington \\ ajko@uw.edu
}

\begin{abstract}
Inclusive design is important in today's software industry, but there is little research about how to teach it. In collaboration with 9 teacher-researchers across 8 U.S. universities and more than 400 computer and information science students, we embarked upon an Action Research investigation to gather insights into the pedagogical content knowledge (PCK) that teachers need to teach a particular inclusive design method called GenderMag. Analysis of the teachers' observations and experiences, the materials they used, direct observations of students' behaviors, and multiple data on the students' own reflections on their learning revealed 11 components of inclusive design PCK. These include strategies for anticipating and addressing resistance to the topic of inclusion, strategies for modeling and scaffolding perspective taking, and strategies for tailoring instruction to students' prior beliefs and biases.
\end{abstract}

\section{CCS CONCEPTS}

- Human-centered computing $\rightarrow$ HCI design and evaluation methods; • Applied computing $\rightarrow$ Education;

\section{KEYWORDS}

Inclusive design; pedagogical content knowledge; design methods

\section{ACM Reference Format:}

Alannah Oleson, Christopher Mendez, Zoe Steine-Hanson, Claudia Hilderbrand, Christopher Perdriau, Margaret Burnett and Amy J. Ko. 2018. Pedagogical Content Knowledge for Teaching Inclusive Design. In ICER '18: 2018 International Computing Education Research Conference, August 13-15, 2018, Espoo, Finland. ACM, New York, NY, USA, 9 pages. https: //doi.org/10.1145/3230977.3230998

\section{INTRODUCTION}

Although most computer science classes in higher education focus on the engineering of software, an increasing number of students take human-computer interaction (HCI) classes, learning the design of software as well. These two distinct skills-deciding what

Permission to make digital or hard copies of all or part of this work for personal or classroom use is granted without fee provided that copies are not made or distributed for profit or commercial advantage and that copies bear this notice and the full citation on the first page. Copyrights for components of this work owned by others than ACM must be honored. Abstracting with credit is permitted. To copy otherwise, or republish, to post on servers or to redistribute to lists, requires prior specific permission and/or a fee. Request permissions from permissions@acm.org.

ICER '18, August 13-15, 2018, Espoo, Finland

(C) 2018 Association for Computing Machinery.

ACM ISBN 978-1-4503-5628-2/18/08_..\$15.00

https://doi.org/10.1145/3230977.3230998 to make (design) and deciding how to make it (engineering)-are both critical to being an effective software professional. In companies without designers (e.g., small startups or companies lacking a design culture), engineers are often responsible for user interface design [23]. In many open source projects, software engineers are the gatekeepers to user experience design decisions [24]. In large software companies, engineers manage and collaborate with designers to make design decisions [26]. In all of these settings, a robust understanding of user experience design is key.

In today's software industry, however, a grasp of design is not enough: software professionals must also understand inclusive design*. Numerous issues exist today with gender and diversity in software companies: software has repeatedly shown failures to be accessible, usable, and/or functional for diverse populations (e.g., $[1,3,5,25])$. With many software companies exploring ways to improve their cultures and the inclusiveness of what they design, understanding how to teach inclusive design to the students who will design tomorrow's software has never been more important.

Unfortunately, inclusion aside, teaching even basic design skills is hard. Some HCI teachers simply avoid teaching design, focusing instead on the theoretical and formal foundations of $\mathrm{HCI}$ research that are well-described in textbooks, but providing little connection to the broader skills involved in design [9]. Research exploring ways to engage students in design practice reports significant challenges in knowing how to teach these methods. For example, Reimer [30] incorporated hands-on, studio-based learning and found that students rated the class as more difficult, more confusing, and more work-intensive than traditionally-taught CS classes. McCrickard et al. [28] used case studies to teach design in a way that students reported as more enjoyable, but the teachers in the study struggled to motivate students to engage with the cases. Hundhausen et al. [21] investigated using a "prototype walkthrough" method in class, finding that students were able to ground their critiques in evidence, but that much of students' learning might be explained by teacher expertise. Studies like these reveal that not only is teaching design hard, but that we do not yet know why it is hard, or even what knowledge is required to teach it successfully. We know even less about teaching inclusive design to computer science students.

In education research, this missing knowledge is referred to as pedagogical content knowledge (PCK). Originally introduced by Shulman [32], PCK is the intersection of pedagogical knowledge

\footnotetext{
* Inclusive design differs subtly from accessibility in that accessibility is about designing for a particular underserved population (e.g., Facebook for blind users) whereas inclusive design is about designing for a broad spectrum of populations (e.g., Facebook for both sighted and blind users).
} 
(background in effective teaching techniques and practices) and content knowledge (background in the subject being taught). Shulman examined teachers' experiences through the lens of how their knowledge set contributed to their successes or failures. When expert teachers possessed some knowledge about how to teach specific course content that novices did not, and when the novice teacher was less successful in their teaching efforts, Shulman called the knowledge PCK for the topic.

PCK is not general. To the contrary: prior work shows that PCK is specific to the topic at hand (e.g., photosynthesis, quadratic equations) and to the audience [14]. In past research on PCK in a range of fields (including literature and geography [32], chemical and biological sciences [14,22], math [19, 32], and computer science [20]), results show that even measuring PCK is domain-specific [18].

Recent surveys of research on PCK in STEM fields shows that teachers with better-developed PCK for their topic often see evidence of better learning in their students [7]. PCK is critical even when teachers have exceptionally high content expertise: FernandezBalboa and Stiehl's study of PCK in higher education found that even the most exceptional teachers needed PCK [10].

For this exploration into PCK for teaching inclusive design, we chose to investigate as many issues as we could for teaching one inclusive design method rather than a broad but more shallow coverage of multiple methods. The inclusive design method we used as our lens into the PCK of teaching inclusive design is GenderMag [5]. GenderMag allows us to explicitly focus on inclusivity (in this case, gender inclusivity), rests on well-established foundations, and has been shown to be effective at uncovering inclusiveness issues that affect all genders in software, with the most success in finding issues that disproportionately affect women $[2,3,8]$.

To investigate PCK necessary for this topic, we followed methods of prior work, looking to both novice and expert teachers to identify the PCK required $[14,22,32]$ to answer the following research question: what PCK do teachers need to teach GenderMag effectively?

This paper contributes:

(1) An analysis of risks to student learning that teachers may encounter when teaching inclusive software design methods in higher education, and a set of mitigations to address these risks.

(2) Evidence for the existence of resistant learners in inclusive design courses and strategies to reduce resistance.

(3) An explicit set of inclusive design PCK.

\section{BACKGROUND: GENDERMAG}

In HCI, there are a range of methods for finding usability problems in designs. Some are empirical, including usability testing and A/B testing, gathering problems as they occur during use. Others are analytical, using principles and argumentation to predict issues that may occur during future use. The GenderMag [3, 5] inclusive design inspection method falls into the analytical category.

GenderMag integrates specialized personas [17] that cover an array of cognitive characteristics together with a specialized Cognitive Walkthrough (CW) [27, 35]. To evaluate a system's gender inclusiveness using GenderMag, a small group of software professionals (e.g., software developers, HCI experts, software managers, etc.) walk through a scenario in their system, step by step, through the eyes of one of the GenderMag personas. At each step, they decide whether their persona (e.g., "Abby") will (1) know what to do and, (2) if Abby performs the action, whether she will know that she is progressing toward her goal. Multiple real-world technology teams have used GenderMag to identify gender-inclusiveness issues in a wide array of systems, with useful results $[2,3,8]$.

To use GenderMag correctly, learners must understand both the process described above and the four personas. The GenderMag personas-Abby, Patricia, Patrick, and Tim-rest on five facets related to technological problem-solving styles: motivations for using tech; information processing style (IPS); computer self-efficacy; learning style (by process or by tinkering); and attitude toward risk (Figure 1). For example, on the facet "learning style," Tim loves to tinker with software features and sometimes forgoes finishing a task in favor of exploring software, whereas Abby likes to learn a process first and then fill in with details of the features to carry it out.

Each persona has different facet values to reflect the segment of the population that they represent. Abby represents the facet values whose proportions disproportionately skew towards females, Tim represents the facet values that disproportionately skew towards males, and the two "identical twins" Pat(ricia) and Pat(rick) fill in values near the middle of the spectra of facet values $[5,6]$. Of the four personas, the Abby persona provides the strongest lens to unearth gender-inclusiveness issues in the user experience because, as prior work has shown, software is often inadvertently designed around the way males tend to use software $[2,3]$.

\section{METHOD: ACTION RESEARCH}

Unlike prior work on PCK [14], we chose Action Research as the research method for our investigation into inclusive design PCK. Action Research is a form of longitudinal field study conducted by a group facing a problem (in our case, teachers wanting to effectively teach inclusive design). Field work in Action Research involves continuous reflection on the nature of that problem while also trying to address it $[15,33]$. Action Research is unlike other empirical studies in that it does not attempt to "control" the setting being observed; instead, the goal is to intervene and learn through

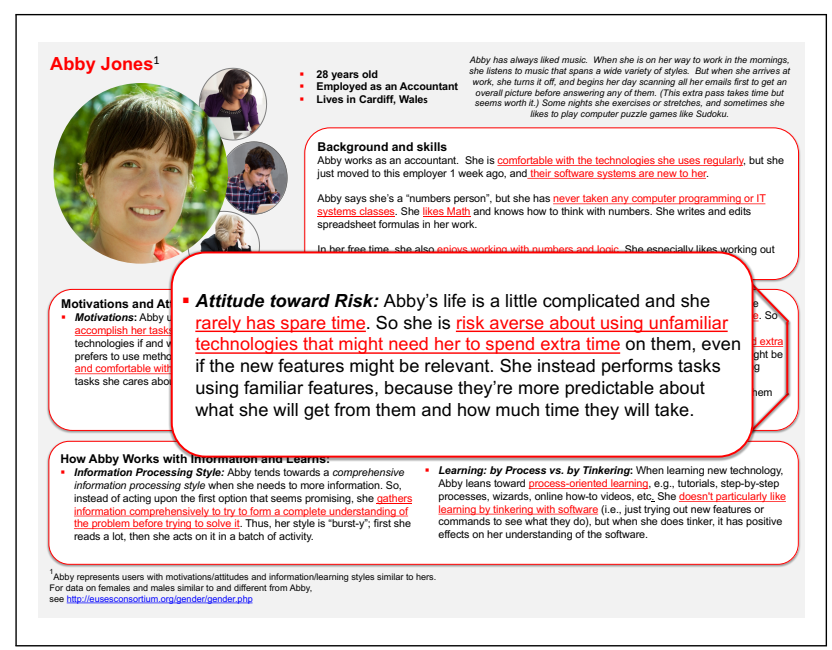

Figure 1: Abby is a "multi-persona," meaning that she has multiple appearances and her demographic portions are customizable [17]. One of the facets is blown up for legibility. 
that intervention. Participants often act as researchers themselves, using data to refine theories of the problem, which in turn informs interventions and further data gathering. Action Research has been used in education research for decades [36].

This cycle of theoretical refinement relies on triangulationassessing the extent to which multiple sources of evidence suggest the same explanation of a problem-to establish credibility and validity of interpretations. Toward this end, we collected data across six sources: (1) interviews with the teacher-researchers about their experiences, (2) emails from teacher-researchers with additional observations, (3) materials the teacher-researchers created to teach their courses, (4) observations in the teacher-researchers' courses, (5) individual students' feedback about the content, and (6) students' responses on course evaluation surveys.

\subsection{The participants}

We had two types of participants: (1) "teacher-researchers," higher education faculty who incorporated gender-inclusive design into their courses and reflected on their practices and (2) students in the teacher-researchers' classrooms. We engaged nine teacherresearchers. Only two had experience teaching GenderMag in college courses. This enabled us to investigate both the novice discovery of PCK and the expert reflection on PCK. One teacher-researcher self-identified as an expert at teaching GenderMag, while the others identified as novices. We designate expertise with " $\mathrm{X}$ " or "N" in participant identifiers. The nine teacher-researchers integrated GenderMag into 12 courses overall (Table 1). Courses were located in eight different U.S. states, reaching more than 400 students.

\subsection{The on-line community}

Prior work shows that community enhances teachers' acquisition of PCK, fostering relationships through which to share knowledge and materials [13]. To facilitate sharing, we created a wiki (Figure 2) and invited the teacher-researchers to contribute to it. The wiki contained diverse materials: slide decks with lecture modules on various portions of the GenderMag method, homework assignments that scaffolded practice of GenderMag walkthroughs on example websites, suggested readings, in-class activities such

Table 1: Teacher-researchers and students by course. The six courses in which students performed a GenderMag walkthrough are marked with asterisks.

\begin{tabular}{cllc}
\hline Teacher & Course topic & Level & \# Students \\
\hline T1N & HCI & Undergrad & 61 \\
T1N & HCI & Graduate & 15 \\
T2N & HCI: Design* & Undergrad & 37 \\
T3X & HCI: Design* & Mixed & 35 \\
T3X & Seminar: Diversity in Tech & Graduate & 16 \\
T3X & Seminar: Ethics of Tech & Undergrad & 59 \\
T4N & HCI: Usability* & Undergrad & 59 \\
T5N & HCI: Usability & Graduate & 29 \\
T6N & SE: Capstone Project* & Undergrad & 27 \\
T7N & SE: Fundamentals & Undergrad & 83 \\
T8N & SE: Game Dev* & Mixed & 21 \\
T9N & SE: Internet Dev* & Graduate & 25 \\
\hline
\end{tabular}

as an interactive GenderMag walkthrough activity to be done in class, the current version of the GenderMag kit [4], and test questions. We built some of the wiki's materials ourselves; the rest were contributed over time by teacher-researchers in this study and by other teachers who have taught GenderMag.

\subsection{The data}

Of our six data types, three came from the teacher-researchers. First, we conducted interviews with the teacher-researchers just after they had finished preparing for their class but before class (usually a day before or the day of class). We interviewed them again as soon after class as possible, also collecting any teaching materials they had created. If the teacher-researchers taught GenderMag over multiple classes, we held multiple interview sessions. One teacherresearcher was not available for interviews, and instead sent us an open-ended email with experiences and reflections.

Prior work shows that teachers often have difficulty verbalizing PCK [32]. Thus, we focused the interviews on the gaps that teachers perceived between their preparation for the course and the outcome of that preparation, based on their perceptions of student reactions to the material. (The complete set of interview questions is available at https://sites.google.com/site/gendermagteach/ appendix-a-interview-questions.) We suspected these gaps would be particularly salient for those who were teaching GenderMag for the first time. We video- and audio-recorded interviews for later transcription and analysis. In total, the interviews and email produced 141 responses to interview questions.

Three data sources came from students: class observations, studentwritten feedback, and student surveys. For two courses, researchers observed pedagogy and student behavior, for a total of 230 observations. In six courses across four universities, teacher-researchers provided an anonymous free-form questionnaire asking students to reflect on their learning of GenderMag, producing 260 comments. Two teacher-researchers also gathered end-of-term impressions about GenderMag, producing 12 comments and 132 five-point Likert-style responses.

\begin{tabular}{|c|c|}
\hline $\begin{array}{l}\text { GENDERMAG-TEACH } \\
\text { HOME }\end{array}$ & GenderMag-Teach \\
\hline $\begin{array}{l}\text { 1. WHY TEACH/WHAT } \\
\text { SKILLS? }\end{array}$ & \\
\hline 2. HOW TO TEACH & \\
\hline 3. LECTURE SLIDES & Welcome to the hol \\
\hline $\begin{array}{l}\text { 4. IN-CLASS ACTIVITIES \& } \\
\text { HANDOUTS }\end{array}$ & Welcome to our beta collaboratis \\
\hline 5. HOMEWORKS & materials on the site for your cla: \\
\hline 6. READINGS & email then to gendermag.methor \\
\hline 7. EXAMPLE QUESTIONS & address.) \\
\hline 8. FILE CABINET & If you have questions about the \\
\hline $\begin{array}{l}\text { 9. DISCUSSION BOARD } \\
\text { 10. FREQUENTLY ASKED } \\
\text { QUESTIONS }\end{array}$ & $\begin{array}{l}\text { Right now, the GenderMag-Teac } \\
\text { through the lens of pedagogical }\end{array}$ \\
\hline
\end{tabular}

Figure 2: Structure of the GenderMag-Teach community wiki. Available in full at the GenderMag site (http:// gendermag.org/). 


\subsection{Analysis}

We began by analyzing the student behavior data, since teacherresearchers' reflections were relative to student behavior. We performed affinity diagramming on the 502 observations and student reflections in these data to inductively generate categories of issues with students' learning of inclusive design. This resulted in the seven issues shown in Table 2. Two researchers then qualitatively coded the reflections and observations, reaching $97.6 \%$ agreement on $21.24 \%$ of the data (Jaccard index). We then coded the 141 teachers' interview responses using these same issue types, to align the teacher data with the student data. Finally, we derived the PCK from the teacher-researchers' reflections about each issue, drawing upon their judgments of students' difficulties and the pedagogy that helped students overcome them.

\section{RESULTS}

Two of the courses collected 5-point Likert-scale questions as part of their universities' end-of-term student teaching evaluations, enabling us to measure those students' own perceptions of their learning. Their 132 responses are summarized in Figure 3.

Qualitative data from other courses corroborate these data, with teachers and students commenting upon the students' engagement, understanding, and reflections upon GenderMag:

T5N: "People were interested, I think people understood why I integrated GenderMag when I teach personas."

$\mathrm{T} 2 \mathrm{~N}$ : "Some ... were visibly excited about the idea that there was a method that had anything at all to do with inclusion.... Something about the idea that there's a well-defined skill or process ..."

T2N-Student (quiz response): "GenderMag makes use of predefined personas in order to see how your design functions according to a variety of users. These personas vary in both experience and motivation, analyzing your design from many perspectives."

T4N-Student (on handout): "Do persona facets ever conflict so greatly that an interface cannot be made?"

T9N: "She [a student] is enthusiastic ... kind of using it as an excuse to brainstorm and show how she could think through other applications of this ..."

These results provide a context for the PCK results that follow, which are summarized and evaluated in Table 3 in the Discussion. We can view positive learning outcomes such as those in Figure 3

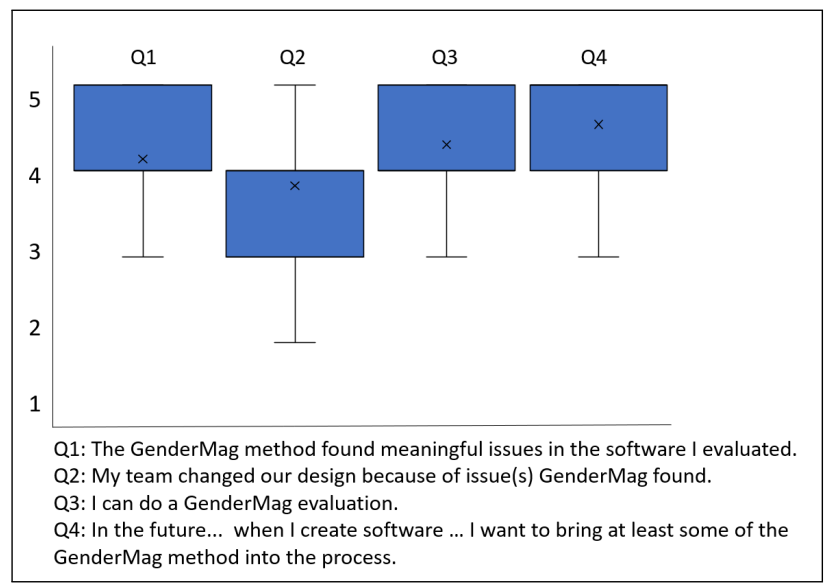

Figure 3: Student evaluations of their own learning ( 1 =strongly disagree, $5=$ strongly agree), with 132 responses. On all four questions, students rated their understanding and application of the material positively.

and in the above qualitative data as being due in part to teachers' mastery of requisite PCK, and we can view learning difficulties in the sections to follow as being due in part to teachers' PCK gaps.

\subsection{PCK for teaching the foundations}

Risk and Prevalence: One risk is that some students can be uncertain about the effectiveness and utility of GenderMag unless they know there are foundational data backing the method. For example:

T2N-Student: "How do the personas account for diverse users? i.e., not 'normal' users."

T2N-Student: "Why is GenderMag different? What makes it unique besides 4 personas compared to any other cognitive walkthrough for a product?"

Foundations issues appeared in nine of the twelve courses (Table 2 ), and they were the most prevalent risk encountered. Some of the mitigations in upcoming sections rest upon solid foundations.

Mitigation and PCK: To mitigate this risk, teacher T3X described a strategy s/he used: first introduce the GenderMag personas including the foundations and evidence base behind them, then have students build analogous personas, and only after these

Table 2: Data instances and courses in which each learning issue was observed. Denominators are the number of instances or courses in which that issue could have arisen. The six courses are the same marked in Table 1 as having done walkthroughs.

\begin{tabular}{|c|c|c|c|}
\hline Problem & Description & Data Instances & Courses \\
\hline $\begin{array}{l}\text { Research } \\
\text { foundations }\end{array}$ & $\begin{array}{l}\text { Students asked questions about the research foundations of GenderMag or whether } \\
\text { other inclusive design methods exist. }\end{array}$ & $121 / 643$ & $9 / 12$ \\
\hline Persona \& facets & $\begin{array}{l}\text { Students did not understand the personas' facets, how the facets apply to interface } \\
\text { features beyond examples provided, or used facets incorrectly. }\end{array}$ & $25 / 643$ & $5 / 12$ \\
\hline $\begin{array}{l}\text { Walkthrough } \\
\text { process }\end{array}$ & $\begin{array}{l}\text { Student incorrectly executed the walkthrough methodology, or reported the walk- } \\
\text { through as pointless or tedious. }\end{array}$ & $49 / 482$ & $4 / 6$ \\
\hline Theory of Mind & $\begin{array}{l}\text { Students had trouble taking the perspective of the persona or viewing the persona } \\
\text { holistically (e.g. using one example from the description to define the persona). }\end{array}$ & $19 / 482$ & $4 / 6$ \\
\hline "I" methodology & Students conducted a walkthrough as if they were using the interface, not the persona. & $7 / 482$ & $1 / 6$ \\
\hline Bias & Students stereotyped use of technology, e.g., "all men" or "all women." & $13 / 643$ & $8 / 12$ \\
\hline Resistance & Students expressed disengagement or disinterest in GenderMag. & $55 / 643$ & $9 / 12$ \\
\hline
\end{tabular}


activities move on to introducing the GenderMag process. Teacher T3X used this PCK to plan for later sessions:

T3X: "When I finally do present GenderMag, which is probably about a month from now, the students will be so used to Abby and her facets, and other facets of personas (the ones they've been developing), that there's not going to be any pushback... they're just going to be really bought into it at that point."

PCK1-Framing: Providing foundations first can give students the capacity to understand and engage with inclusive design methods.

Other PCK related to foundations came from resources that teachers used to build students' conceptual foundations of inclusive design. Teacher T5N found it useful both personally and for their students to read research papers about GenderMag before practicing the method in class, as the papers clearly argued the rationale and need for the method. Experiences like this about where the "best knowledge" about GenderMag resided was also critical PCK:

T5N: "First I read, and if there are specific research papers associated with it I will also read those research papers. Also I go to YouTube, because some people put up video lectures on a particular topic, and those are very efficient ways of learning ... some of those videos I share with my students."

T5N: "It was really helpful to assign the CHI paper [17] as reading before today's lecture because students were definitely ready to talk about it and they really understood why I am using this."

PCK2-Credibility: Providing students credible resources can convince them inclusive design methods are valid and useful.

\subsection{PCK for teaching the personas and facets}

Risk and Prevalence: Another risk was students misunderstanding the problem-solving facets that defined the GenderMag personas. Persona and facet issues appeared in five out of the twelve courses (Table 2). For example:

T2N-Student: "Why were these five facets the ones picked? (More specifically what insight do they offer?)"

T5N also encountered issues explaining the differences between personas' Information Processing Style and Learning Style:

T5N: "I thought those five facets were orthogonal in a sense ... but as

I explained to students, they are very related to one another. For example, information processing style and their learning style, I feel like they are very related... I think students understood why we use GenderMag, but I am not confident that they understood those five facets..."

Mitigations and PCK: These issues suggest two PCK gaps: a gap in deep enough content knowledge about the facets to help students understand the relationships among them, and a gap in strategies for presenting these relationships.

One instance of the content depth gap was revealed when T5N requested a deeper understanding of the facets. In response, an expert researcher in the GenderMag method provided a detailed explanation of the nuanced relationships among the facets and examples of how people with these facets might act for use in teaching (Figure 4). The clarifications in that message aimed at the PCK gaps that T5N had experienced.
PCK3-ContentKnowledge: Content knowledge of the facets can help teachers explain to students each facet's impacts on how a user might interact with software.

For PCK on how to convey the distinctiveness of each facet, T3X's presentation strategy showed promise. As class observation data showed, every time T3X introduced a new problem-solving facet, $\mathrm{s} /$ he immediately followed the facet's name with a concrete description. For example, T3X began describing the Motivations facet by naming it and then reframing it as "Why is the persona sitting in this chair [in front of the computer with this software]?"

Such "concretizations" may have helped students to ground the further elaboration that followed. For example, later in the course as T3X's students performed a GenderMag walkthrough, researchers observed the students successfully identifying design issues relating directly to the personas' facets, such as the persona Tim's propensity to tinker with software:

T3X-student: "I was Tim [for the walkthrough], and would like to tinker, but there was no back button [to recover from failed tinkering]."

PCK4-Concretization: Reframing facets in concrete ways to explain persona behavior can model how students should use the facets to predict persona behavior.

\subsection{PCK for teaching the process itself}

Risk and Prevalence: Students performed the GenderMag process (known as GenderMag walkthroughs) as in-class exercises in six courses. In four of these courses, students became confused about how to perform the walkthrough correctly (Table 2, row Walkthrough processes). Confused students may not be able to finish their walkthroughs successfully, which could translate into reluctance to use inclusive methods in the future.

For example, in T2N's course, instead of following the sequence of actions the designer intended, a group of students drifted into a sequence they thought Abby might pursue. This led to a "dead end" in being able to fulfill the subgoal they had started with, so they were unsure how to proceed:

T2N-Student: "What should we do if we end up on a different page?" Researcher's notes: "This team had stopped following the walk-

through steps and decided Abby would do something else. Ended up on the wrong [website] page and unsure how to proceed."

T3X's course also showed confusion about the correct process:

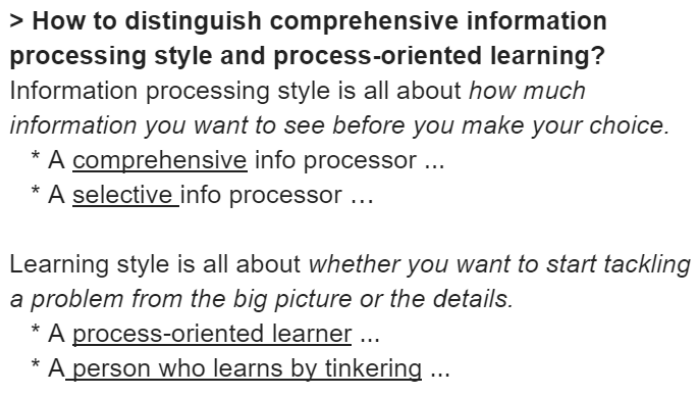

Figure 4: Snippets of the message sent to $\mathrm{T} 5 \mathrm{~N}$ describing distinctions between facets. The email also contained concrete examples of how users with the facets might use software. 
Researcher's notes: "At both tables with multiple teams, one team would follow the other team's lead. Such as flipping or changing forms, or [one team] would listen in to the other's conversation as a launching point for their own [conversation]."

Mitigation and PCK: T3X's mitigation strategy for this risk relied on the student foundations, prompting students with questions and coaching them during their hands-on activity to help them understand the walkthrough components. For example, as one team attempted to come up with a scenario, subgoals, and actions for their walkthrough, T3X provided corrective clarifying feedback:

T3X: "Why are they in this app? What is their motivation for sitting in front of their screen?"

Researcher notes later during the class: "Trouble generating subgoal ...If $<T 3 X>$ didn't intervene this would have gone poorly."

T3X-Student: "Can we use subgoal or the scenario when answering the action question?"

T3X: "Yes you can reference both if it applies to your reasoning."

T3X-Student: "So is the 'right thing' the action? [Referring to wording on the walkthrough forms]"

T3X: "Yes, it is what <student> defined to us as the action."

PCK5-Modeling: Modeling correct process for students both before and during hands-on practice can help students improve their use of an inclusive design process.

\subsection{PCK for increasing students' application of "Theory of Mind"}

Risk and Prevalence: Four of the six courses that performed GenderMag walkthroughs revealed PCK gaps relating to Theory of Mind. Theory of Mind is the human ability to reason and make inferences about another's feelings, desires, intentions, and goals [29, 31]. Methods like GenderMag leverage this ability to help evaluators predict the usability of a product by people different from themselves. Thus, learning how to apply GenderMag depended on the degree to which students could take on the perspective of the persona. But some students had difficulties doing so.

For example, ten T2N students wrote comments about Theory of Mind difficulties "channeling" the persona, such as:

T2N-Student: "It was difficult to determine what I would do vs what Abby would do."

T2N-Student: "Really hard to put yourself in others shoes."

T2N-Student: "Intuitively I was considering the general understand-

ing of users and it is difficult to consider the persona if it doesn't

make sense based on personal experience."

Another way Theory of Mind issues manifested was students using a single example from the facet description to entirely define the persona, such as the Learning Styles example of Abby preferring tutorials over tinkering to learn technology. For example:

T3X-Student: "No, she wants to watch a tutorial."

T3X-Student: "I don't think she would be here. She likes wizards and this isn't that."

Mitigation and PCK: To mitigate risks like these, T3X repeatedly emphasized that students should immerse themselves in the persona's perspectives. For example, during T3X's class activity with students doing GenderMag walkthroughs on example software prototypes, researchers observed T3X telling different groups of students...:
T3X: "Your job at this table is to become Abby. Your job [at another table] is to become Tim. Don't think about anyone but Tim. ... Your brain becomes that person's brain-absorb everything about that person."

PCK6-TheoryOfMind: Coaching students to immerse themselves in the persona can help them with their "Theory of Mind" abilities to see software through the eyes of a persona.

\subsection{PCK for reducing " $\mathrm{I}$ " methodology}

Risk and Prevalence: One way specific failures of perspective taking manifested was when students performed a GenderMag walkthrough not as the persona, but instead as themselves: "I would know to click this button to advance to the next page, so of course Abby would do that too." Some teacher-researchers described this as "I" methodology. All seven instances observed of "I" methodology (Table 2) occurred in T2N's course. For example:

T2N-Student: "It is a little difficult to walkthrough based on a persona.

At multiple parts I was thinking what I would do in this situation."

Use of "I" methodology has also been reported in GenderMag work in industry [16], so a few suggestions for warding it off had been posted to the GenderMag-Teach community wiki. For example, following one of these suggestions, T2N cautioned their class to "stay true to the persona." Even so, some of T2N's students had more difficulty than others with stepping into another's cognitive shoes. T2N reflected on their students' range of success staying clear of "I" methodology pitfalls:

$\mathrm{T} 2 \mathrm{~N}$ : "Some students seem to have no problem just slipping right into that mindset of 'Abby's a different person, I understand that different people have different ways of thinking about things, I'm going to speculate from her perspective.' And other students ... [at least] recognize that their perspectives aren't the only ones, and that they don't understand other people's perspectives. But there are still students that don't."

Mitigation and PCK: T3X had run into "I" methodology issues before in prior courses, and had found a way to mitigate it. T3X's method was to watch for it to arise during class GenderMag walkthroughs. As soon as an instance arose, T3X would intervene to ask the student to rephrase what they had just said, replacing "I" with the name of the persona they were using (e.g., "Abby"). As T3X explained in one of their pre-teaching interviews just before a class in which students would run GenderMag walkthroughs:

T3X: "I'll remind them of the rules, such as they're never allowed to say "I" or "you" or "the user," they have to say Abby ... or Tim [the GenderMag personas]."

PCK7-Averting "I": Listening for uses of "I" during in-class activities and prompting students to use the personas' names can reduce use of "I" methodology and increase perspective-taking.

Another mitigation strategy, used by T6N, was to task their students with writing persona "backstories" for the persona they used. For example, one team modified the Abby persona, turning her into "Jenn." Part of the backstory they devised for her was: T6N-Student: "Jenn needs to find housing for her 18 years old son who is deaf and transferring to $<$ University>."

There were no "I" methodology instances observed in either of the courses that used these interventions. 
PCK8-Engagement: Tasking students to modify non-essential parts of inclusive design method materials, such as background information, can increase engagement with the materials through a heightened sense of ownership.

\subsection{PCK for addressing gender biases}

Risk and Prevalence: Biases in the form of gender stereotyping arose in eight of the twelve courses (Table 2). These arose when a student overgeneralized or gender-stereotyped a persona's ability to use technology or to problem-solve.

For example, one of T4N's students wrote the following on their handout after learning about the GenderMag personas:

T4N-Student: "Why are boys reckless?"

We interpreted this student's comment to be about the Tim persona (whose problem-solving traits are statistically more common in males than in females). Tim likes to learn by tinkering with software and also tolerates risk in software. These two traits may have informed this student's characterization of males as "reckless".

Mitigation and PCK: Stereotyping is an ingrained human characteristic [34] that is difficult to eliminate entirely. Furthermore, framing GenderMag as a way to find gender-inclusiveness issues makes the concept of gender highly salient. This salience of gender automatically leads to gender stereotype activation [11]. Thus, teachers reported either proactively finding ways to reduce its number of instances or reactively explicitly addressing it head-on.

$\mathrm{T} 4 \mathrm{~N}$ pointed out one reactive mitigation strategy, observing some students asking about the evidence base behind gender differences in problem-solving. Evidence (e.g., a qualitative study showing how different problem-solving strategies can result in equally effective solutions [12]) helped students ground their decisions in solid foundations rather than stereotypes. One instance of this strategy occurred in teacher T3X's lecture on GenderMag's foundations:

T3X: "This [pattern of data] holds strongest for male versus female developers. Why do you think this is?"

T3X-Student: "Women are more emotional, they don't like technology."

T3X: "Not true, they [in these data] are software developers."

PCK9-RefutingStereotypes: Pointing students to the evidence underlying inclusive design methods can help students connect their work to foundations rather than stereotypes.

As for proactive strategies to address stereotyping, our data showed that practicing an actual GenderMag walkthrough, rather than just learning about it conceptually, had fewer instances of stereotyping. In fact, all but one of the instances occurred in courses without a walkthrough activity or before the walkthrough activity. These data are corroborated by a prior study investigating stereotyping in the presence of the GenderMag inclusive design method, which found that groups that performed a GenderMag walkthrough gender-stereotyped personas less than those who did not do a walkthrough-and both groups gender-stereotyped the personas less than empirical norms of how much people genderstereotype actual people [17].

PCK10-ReducingStereotypes: Having students perform the inclusive design process can reduce tendencies to stereotype members of populations unlike themselves.

\subsection{PCK for addressing resistant learners}

Risk and Prevalence: Stereotyping (or fears of it) also manifested in students as resistance to learning about inclusive methods. Some of the teachers foresaw this resistance:

T5N: "I really hope the students don't take it as a way of stereotyping genders ... From previous experience, I found that when students create personas that are very shallow level, that's what they do, they stereotype a particular gender or a particular age group. "

Other teachers predicted that GenderMag's explicit focus on gender might elicit a negative response. T8N, who taught GenderMag in their undergraduate-level game design course, predicted that the name "GenderMag" would generate resistance:

T8N: "[The] title for the project ... will turn people off before they understand how valuable it is."

In nine of the twelve courses, these teachers' fears came to pass. One type of resistance came from some students concerns that GenderMag might promote gender stereotyping:

T1N: "Some women [in the class] felt that the personas exaggerated the differences between genders, and created a perception that women were technologically helpless ... while it succeeded in drawing engineers' attention to the shortcomings of the software, it also reinforced unhelpful stereotypes... This was not the first time in my teaching that students were alarmed by an intervention that highlighted differences between genders."

A second kind of resistance involved students who overtly stereotyped the personas:

$\mathrm{T} 7 \mathrm{~N}$ : "People were not taking Abby seriously'she is scared of pressing a button' ... trivializing the facets."

Some teachers did not have a ready strategy to mitigate this risk: T7N: "I didn't know how to make them be serious ... There were a bunch of people who were not even trying."

A third type of resistance was students not seeing the point of learning about GenderMag and inclusive design methods. One student in T3X's course showed evidence of this kind of resistance on an evaluation response: when asked what could be done to improve instruction, T3X-Student simply replied "Less GenderMag."

These examples show the existence of resistant learners in inclusive design classrooms: students who not only are unmotivated to learn the material, but who actively dispute or trivialize the concepts of inclusive design.

Mitigation and PCK: Teachers responded to resistance in three ways. One mitigation was to simply avoid talking about gender, using language of inclusion instead. When T1N taught GenderMag in their undergraduate HCI course the following term, s/he modified their approach to include an active-learning, in-class activity that allowed students time to get their questions answered. S/he elected to remove any mention of gender from their second lesson and focus solely on the persona's software usage styles as a lens for inclusivity. T1N found that this intervention helped students understand the importance of inclusiveness in software without potentially getting caught up on the gendered nature of the topic. T1N also observed, however, that this came at the cost of not fully leveraging GenderMag's foundations, because to do so would require bringing up gender.

A second strategy involved situating gender in the broader goal of inclusion and discussing the primary benefits of inclusion. For 
example, T3X spoke to the benefits of inclusive design when a student doubted its efficacy:

T3X: "Somebody else doubted whether you could have a 100 percent perfect interface for everyone, and I totally agreed, and said we're not aiming for 100 percent here, we're just aiming for 'better.' He bought that."

T3X reported that after that interaction, the student was enthusiastic and engaged in the rest of the lecture. Focusing on inclusiveness for its own sake may thus motivate an otherwise resistant subset of students.

A third strategy was to mitigate resistance by focusing on the secondary benefits of inclusion. In their courses on GenderMag, $\mathrm{T} 7 \mathrm{~N}$ mentioned that designing inclusive software can increase a product's user base:

T7N: " $50 \%$ of people are women, it's better economics."

T6N made a similar point to their class:

T6N: "They like the idea that we have to design software for everyone. I used the illustration that if only half the market wants to buy your software, that's not going to be a very successful product."

PCK11-HandlingResistance: Relating inclusive design methods' utility to the broader goal of inclusive appeal and/or to greater market share can mitigate the risk of students' resistance and motivate them to learn inclusive design.

\section{DISCUSSION AND CONCLUDING REMARKS}

The goal of our study was to uncover what PCK teachers need to teach inclusive design through the lens of GenderMag. We found at least four major categories of PCK:

- Students can be skeptical about gender differences in problemsolving, which can impede willingness to learn, but are often convinced by research evidence (PCK 1 and 2).

Table 3: Triangulation: Each new PCK was supported by three or more different data sources. (Numbers refer to sections showing instances of the data source.)

\begin{tabular}{l|l|l|l|l|l}
\hline PCK \# & $\begin{array}{l}\text { Interview } \\
\text { \& Emails }\end{array}$ & $\begin{array}{l}\text { Class } \\
\text { Obs }\end{array}$ & $\begin{array}{l}\text { Student } \\
\text { Feedback }\end{array}$ & $\begin{array}{l}\text { Teaching } \\
\text { Materials }\end{array}$ & $\begin{array}{l}\text { Prior } \\
\text { Work }\end{array}$ \\
\hline PCK1-Framing & $\checkmark 4.1$ & $\checkmark$ & $\checkmark$ & & \\
PCK2-Credibility & $\checkmark$ & $\checkmark$ & $\checkmark$ & $\checkmark 4.2$ & \\
$\begin{array}{l}\text { PCK3-Content } \\
\text { Knowledge }\end{array}$ & $\checkmark$ Fig 4 & $\checkmark$ & $\checkmark 4.2$ & & \\
$\begin{array}{l}\text { PCK4- } \\
\text { Concretization }\end{array}$ & $\checkmark$ & $\checkmark 4.2$ & $\checkmark 4.2$ & & \\
$\begin{array}{l}\text { PCK5-Modeling } \\
\text { PCK6- } \\
\text { TheoryOfMind }\end{array}$ & $\checkmark$ & $\checkmark$ & $\checkmark 4.3$ & & \\
$\begin{array}{l}\text { PCK7- } \\
\text { Averting“I” }\end{array}$ & $\checkmark 4.5$ & $\checkmark 4.5$ & $\checkmark 4.5$ & & \\
$\begin{array}{l}\text { PCK8- } \\
\text { Engagement }\end{array}$ & & $\checkmark$ & $\checkmark$ & $\checkmark 4.5$ & \\
$\begin{array}{l}\text { PCK9-Refuting } \\
\text { Stereotypes }\end{array}$ & $\checkmark$ & $\checkmark 4.6$ & $\checkmark 4.6$ & & [11, \\
$\begin{array}{l}\text { PCK10-Reducing } \\
\text { Stereotypes }\end{array}$ & $\checkmark$ & $\checkmark$ & $\checkmark$ & & \\
$\begin{array}{l}\text { PCK11-Handling } \\
\text { Resistance }\end{array}$ & $\checkmark 4.7$ & $\checkmark$ & $\checkmark$ & & \\
\hline
\end{tabular}

- Learning GenderMag's persona facets and walkthrough process requires careful scaffolding before and during active practice of the method. Generalizing to other inclusive design methods, the PCK for leveraging personas should also be useful for considering real people in a target population (PCK 3, 4, and 5).

- Some students struggle with perspective-taking and stereotyping, but prescriptive rules such as avoiding the word "I", corrective feedback, and student production of materials can engage students in more facet-based reasoning (PCK 6, 7, and 8).

- Some students hold gender biases, political stances, and interpersonal fears of discussing gender in a classroom, but connecting goals to evidence, engaging students in practicing a walkthrough, and situating discussion of gender under a broader goal of inclusion can mitigate resistance (PCK 9, 10, and 11).

Although our data was rich, some aspects of our study design limit the internal and external validity of these interpretations. As an Action Research study, we did not attempt to control for teachers' pedagogical knowledge or content knowledge; even had we wanted to, there is a lack of robust measurements for either. Teachers varied in their ability to reflect on their PCK, and both students and teachers varied in their ability to reflect on students' learning, which led to variation in the level of detail in our data across courses. There were also several factors that may have determined what we did and did not observe, such as teachers' existing pedagogical knowledge, whether courses were required or electives, and the teachers' varying degrees of preparation and classroom management skills. Therefore, some of the interpretations we made from the data might be different had we studied other teachers or students. Consistent with Action Research methods, we safeguarded against these limitations through extensive use of triangulation, which we enumerate in Table 3.

Despite the limitations, our results have important implications for research. For example, our data suggest a testable hypothesis: that teachers need a robust understanding of their students' existing perspectives on inclusion in order to successfully connect conceptual content to their prior knowledge, to answer questions during active learning, and to facilitate discussions about inclusive design. Our data also suggest a hypothesis that perspective taking is a critical prerequisite skill for conducting a successful GenderMag walkthrough and that without it, students may struggle or fail to become proficient in inclusive design. Future work should develop ways of measuring the factors and outcomes in these hypotheses so that we may rigorously test them.

Although our research on how to teach inclusive design is just beginning, our results also have implications for teachers. The PCK we present in this paper suggests that with a careful orientation to inclusion, highly scaffolded practice for persona-based walkthroughs, and corrective feedback on this practice, students can successfully perform inclusive design processes, identifying inclusion issues in user experience designs. Through these efforts and further progress in effective teaching of inclusive design, future generations of designers and engineers can be empowered to shape not only novel user experiences, but inclusive ones.

\section{ACKNOWLEDGMENTS}

This work is supported in part by the National Science Foundation under Grants 1735123, 1314399, 1703304, 1314384, and 1528061. 


\section{REFERENCES}

[1] Engin Bozdag. 2013. Bias in algorithmic filtering and personalization. Ethics and information technology 15, 3 (2013), 209-227. https://doi.org/10.1007/ s10676-013-9321-6

[2] M. Burnett, R. Counts, R. Lawrence, and H. Hanson. 2017. Gender $\mathrm{HCl}$ and microsoft: Highlights from a longitudinal study. In 2017 IEEE Symposium on Visual Languages and Human-Centric Computing (VL/HCC). 139-143. https: //doi.org/10.1109/VLHCC.2017.8103461

[3] Margaret Burnett, Anicia Peters, Charles Hill, and Noha Elarief. 2016. Finding gender-inclusiveness software issues with GenderMag: A field investigation. In Proceedings of the 2016 CHI conference on human factors in computing systems (CHI '16). ACM, New York, NY, USA, 2586-2598. https://doi.org/10.1145/2858036. 2858274

[4] Margaret Burnett, Simone Stumpf, Laura Beckwith, and Anicia Peters. 2018. The GenderMag Kit: How to use the GenderMag Method to find inclusiveness issues through a gender lens. (February 2018). http://gendermag.org

[5] Margaret Burnett, Simone Stumpf, Jamie Macbeth, Stephann Makri, Laura Beckwith, Irwin Kwan, Anicia Peters, and William Jernigan. 2016. GenderMag: A method for evaluating software's gender inclusiveness. Interacting with Computers 28, 6 (2016), 760-787. https://doi.org/10.1093/iwc/iwv046

[6] Margaret M. Burnett, Laura Beckwith, Susan Wiedenbeck, Scott D. Fleming, Jill Cao, Thomas H. Park, Valentina Grigoreanu, and Kyle Rector. 2011. Gender pluralism in problem-solving software. Interacting with Computers 23, 5 (2011) 450-460. https://doi.org/10.1016/j.intcom.2011.06.004

[7] Rebecca Cooper, John Loughran, and Amanda Berry. 2015. Science Teachers' PCK. Berry, A., Friedrichsen, P. \& Loughran, J., Re-examining Pedagogical Content Knowledge in Science Education (2015), 60-74.

[8] Sally Jo Cunningham, Annika Hinze, and David M Nichols. 2016. Supporting gender-neutral digital library creation: A case study using the GenderMag toolkit. In International Conference on Asian Digital Libraries. Springer, 45-50. https //doi.org/10.1007/978-3-319-49304-6_6

[9] Anthony Faiola. 2007. The design enterprise: Rethinking the HCI education paradigm. Design Issues 23, 3 (2007), 30-45. https://doi.org/10.1162/desi.2007.23. 3.30

[10] Juan-Miguel Fernandez-Balboa and Jim Stiehl. 1995. The generic nature of pedagogical content knowledge among college professors. 11 (05 1995), 293-306. https://doi.org/10.1016/0742-051X(94)00030-A

[11] Anthony G Greenwald and Mahzarin R Banaji. 1995. Implicit social cognition attitudes, self-esteem, and stereotypes. Psychological review 102, 1 (1995), 4. https://doi.org/doi:10.1037/0033-295X.102.1.4

[12] Valentina Grigoreanu, Margaret Burnett, Susan Wiedenbeck, Jill Cao, Kyle Rector, and Irwin Kwan. 2012. End-user debugging strategies: A sensemaking perspective. ACM Transactions on Computer-Human Interaction (TOCHI) 19, 1 (2012), 5. https: //doi.org/10.1145/2147783.2147788

[13] Allison Gulamhussein. 2013. Teaching the Teachers: Effective professional development. (Sep 2013). http://www.centerforpubliceducation.org/research/ teaching-teachers-effective-professional-development

[14] Jan H. van Driel, Nico Verloop, and Wobbe de Vos. 1998. Developing science teachers' pedagogical content knowledge. 35 (08 1998), 673-695. https://doi.org/ 10.1002/(SICI)1098-2736(199808)35:6<673::AID-TEA5>3.0.CO;2-J

[15] Gillian R Hayes. 2014. Knowing by doing: Action Research as an approach to HCI. In Ways of Knowing in HCI. Springer, 49-68.

[16] C. Hill, S. Ernst, A. Oleson, A. Horvath, and M. Burnett. 2016. GenderMag experiences in the field: The whole, the parts, and the workload. In 2016 IEEE Symposium on Visual Languages and Human-Centric Computing (VL/HCC). 199207. https://doi.org/10.1109/VLHCC.2016.7739685

[17] Charles G. Hill, Maren Haag, Alannah Oleson, Chris Mendez, Nicola Marsden, Anita Sarma, and Margaret Burnett. 2017. Gender-inclusiveness personas vs. stereotyping: Can we have it both ways? In Proceedings of the 2017 CHI conference on human factors in computing systems (CHI '17). ACM, New York, NY, USA, 66586671. https://doi.org/10.1145/3025453.3025609
[18] Heather C. Hill, Deborah Loewenberg Ball, and Stephen Schilling. 2008. Unpacking pedagogical content knowledge: Conceptualizing and measuring teachers' topic-specific knowledge of students. 39 (07 2008), 372-400. https: //doi.org/10.1145/3025453.3025609

[19] Heather C. Hill, Brian Rowan, and Deborah Loewenberg Ball. 2005. Effects of teachers' mathematical knowledge for teaching on student achievement. American Educational Research fournal 42, 2 (2005), 371-406. https://doi.org/10.3102/ 00028312042002371 arXiv:https://doi.org/10.3102/00028312042002371

[20] Peter Hubwieser, Johannes Magenheim, Andreas Mühling, and Alexander Ruf. 2013. Towards a conceptualization of pedagogical content knowledge for computer science. In Proceedings of the ninth annual international ACM conference on international computing education research (ICER '13). ACM, New York, NY, USA, 1-8. https://doi.org/10.1145/2493394.2493395

[21] C. D. Hundhausen, D. Fairbrother, and M. Petre. 2012. An Empirical Study of the "Prototype Walkthrough": A Studio-Based Activity for HCI Education. ACM Trans. Comput.-Hum. Interact. 19, 4, Article 26 (Dec. 2012), 36 pages. https: //doi.org/10.1145/2395131.2395133

[22] N. H. Ibrahim, J. Surif, A. H. Abdullah, and N. A. S. Sabtu. 2014. Comparison of pedagogical content knowledge between expert and novice lecturers in teaching and learning process. In 2014 International Conference on Teaching and Learning in Computing and Engineering. 240-246. https://doi.org/10.1109/LaTiCE.2014.53

[23] Amy J Ko. 2017. A three-year participant observation of software startup software evolution. In Proceedings of the 39th International Conference on Software Engineering: Software Engineering in Practice Track. IEEE Press, 3-12. https: //doi.org/10.1109/ICSE-SEIP.2017.29

[24] Amy J Ko and Parmit K Chilana. 2011. Design, discussion, and dissent in open bug reports. In Proceedings of the 2011 iConference. ACM, 106-113. https: //doi.org/10.1145/1940761.1940776

[25] Amy J Ko and Richard E Ladner. 2016. AccessComputing promotes teaching accessibility. ACM Inroads 7, 4 (2016), 65-68. https://doi.org/10.1145/2968453

[26] Paul Luo Li, Amy J Ko, and Andrew Begel. 2017. Cross-disciplinary perspectives on collaborations with software engineers. In Cooperative and Human Aspects of Software Engineering (CHASE), 2017 IEEE/ACM 10th International Workshop on. IEEE, 2-8. https://doi.org/10.1109/CHASE.2017.3

[27] Thomas Mahatody, Mouldi Sagar, and Christophe Kolski. 2010. State of the art on the cognitive walkthrough method, its variants and evolutions. Intl. fournal of human-computer interaction 26, 8 (2010), 741-785. https://doi.org/10.1080/ 10447311003781409

[28] D. Scott McCrickard, C. M. Chewar, and Jacob Somervell. 2004. Design, science, and engineering topics?: teaching HCI with a unified method. In Proceedings of the 35th SIGCSE technical symposium on computer science education (SIGCSE '04). ACM, New York, NY, USA, 31-35. https://doi.org/10.1145/971300.971314

[29] David Premack and Guy Woodruff. 1978. Does the chimpanzee have a theory of mind? Behavioral and Brain Sciences 1, 4 (1978), 515-526. https://doi.org/10. 1017/S0140525X00076512

[30] Yolanda Jacobs Reimer and Sarah A Douglas. 2003. Teaching HCI design with the studio approach. Computer science education 13, 3 (2003), 191-205.

[31] Dana Schneider, Rebecca Lam, Andrew P Bayliss, and Paul E Dux. 2012. Cognitive load disrupts implicit theory-of-mind processing. Psychological Science 23, 8 (2012), 842-847. https://doi.org/10.1177/0956797612439070

[32] Lee Shulman. 1987. Knowledge and teaching: Foundations of the new reform. Harvard educational review 57, 1 (1987), 1-23. https://doi.org/10.17763/haer.57.1. j463w79r56455411

[33] Ernest T Stringer. 2007. Action Research (3e éd.). (2007).

[34] Phil Turner and Susan Turner. 2011. Is stereotyping inevitable when designing with personas? Design studies 32, 1 (2011), 30-44. https://doi.org/10.1016/j. destud.2010.06.002

[35] Cathleen Wharton. 1994. The cognitive walkthrough method: A practitioner's guide. Usability inspection methods (1994).

[36] Ortrun Zuber-Skerritt. 1992. Action research in higher education: examples and reflections. ERIC. 